\title{
Isabel Fernández
}

\section{Editorial}

\section{Bases para un plan de nación}

L

a presentación del documento Bases para un plan de nación recibió el parabien de los 200 invilados al Ministerio de Asuntos Exteriores, incluso, los diarios matulinos del 17 de enero rezumaban un entusiasmo generalizado. Luego de un año, 1997, en que el crecimiento no fue lo suficiente para aliviar los problemas del desempleo y de la pobreza estructural, el plan de nación venía a decir que algo se puede y debe hacer entre lodos para salir del estancamiento y de la crisis de estabilidad y confianza. Este documento venía a inyectar una dosis de oxígeno a quienes no veían rumbo ni dirección en la gestión pública, al mismo tiempo que tocaba la tecla nacional de la concertación, participación y apertura democrática. Daba la impresión de que el gobiemo quería borrar la imagen de verticalismo e improvisación, al abrir las puerlas a un diálogo nacional.

En sus discursos del 1 de mayo y 1 de junio de 1997, el presidente implícitamente anunciaba un cambio de agujas en la gestión gubernamental. El párтafo introductorio lo explica "como resultado de la voluntad soberana que el pueblo salvadoreño expresó en las pasadas elecciones, dando a las fuerzas políticas el mandato de la concerlación para avanzar de la paz al desarrollo integral de nuestro país" (El Diario de Hoy, 1 de mayo de 1997).

El resultado de las eleciones de 1997 indicaba que había que ensayar algo nuevo para que el desencanto nacional no se tradujese en otro voto de castigo en 1999. Había también otras razones bien objetivas de cara al próximo futuro. Se recomienda "la formulación de un Plan Nacional de Desarrollo, con una visión de mediano y largo plazo, que nos lleve al desarrollo y genere estabilidad y confianza" (ítem, 1 de mayo). "Necesitamos tener una visión de largo plazo para dar estabilidad y continuidad al país, más allá de los períodos de gobiemo, a fin de convertir a nuestro país en un lugar atractivo para la inversión y generación de empleo, que eleven el bienestar y calidad de vida de la población" (ítem, 1 de junio de 1997). 
Desde 1993, año preelectoral, y en 1996-1997 varios institutos e instituciones habían presentado sus respectivas propuestas de consenso, a modo de esquemas de plan de nación. De alguna manera, la comisión del plan de nación recogía estos reclamos de concertación y diálogo. Esto explica que la presentación de este documento se recibiera con general empatía. Algunos comentaristas ven este plan de nación como una "utopía", algo que no existe, pero que sería la norma de lo que debe existir. Calificarlo como utopía es, al mismo tiempo, una alabanza y un temible desafío.

Es una alabanza porque hacía años que no oíamos hablar de un plan de nación, a excepción de los programas trienales del Banco Mundial para nuestro país. El documento oficial eran los programas monetario-financieros del Banco Central de Reserva, demasiado macroeconómicos, economicislas y alejados de - la realidad cotidiana de la mayoría de la población. No llegaban a la comprensión, ni al convencimiento de la mayoría del pueblo, aparte de que siempre enlonaban los mismos estribillos. El plan de nación enuncia, e indirectamente denuncia, problemas concretos en los cinco niveles: político, cultural-educativo, socioeconómico, participación ciudadana e institucional del Estado. Se trata de un documento que lo pueden comprender quienes pueden leer.

A las mayorías les agradará escuchar que el "nudo gordiano", o problema número uno, es la "pobreza estructural, que se asienta en la marginación sociocultural y que deriva, a su vez, de la configuración y el funcionamiento del poder político" (p. 5). Hasta ahora se nos decía que nuestra economía era sana, fuerte y ejemplo a imitar, a juicio de los organismos intemacionales. El plan de nación pone en cuestionamiento esta euforia oficial. Llama la atención que no han habido pronunciamientos específicos de los miembros del comité económico y otros personeros gubernamentales sobre la pertinencia de este plan de nación. Más bien queda la impresión de que este documento presenta una difuminada autocrítica que los comités gubernamentales no se atreven a hacer.

Es una alabanza el que nos presenten un amplio abanico de problemas y desafíos en los cinco niveles mencionados de nuestra convivencia nacional. Pero, al mismo tiempo, es un temible desafío porque a partir del parabien inicial es necesario traducir las bases del plan en formulaciones y propuestas prioritarias y ordenadas. Y aquí es donde la concertación se puede convertir en debate. Hay una frase clave que se cita al Iratar la "redefinición del rol del Estado" y que se aplica a otros ítems. "En la redefinición de los fines del Estado está planteada una discusión de carácter ideológico o doctrinario, cuyo fondo debe hacerse explícito y abordarse con claridad para posibilitar un acuerdo nacional..."(p. 22).

Por supuesto que la redefinición de la función del Estado es uno de los temas hoy día sometidos a debate, a partir de las experiencias continentales de las reformas liberales. Uno de los puntos a debatir es si la modernización del Estado significa encerrarlo en la garita de la "subsidiaridad". Aunque este debate 
aparecerá en análisis más detallados del plan de nación, sirvan como botón de muestra unas líneas extractadas de la reciente revista de ANEP. El autor, Howard J.Wiarda, Universidad de Masachusetts, concluye su artículo sobre la modernización del Estado en América Latina con esta reflexión: "después de la crisis del peso mexicano se ha hecho más lento el paso de las reformas y a través del hemisferio los políticos demócratas están ahora comprensiblemente renuentes a impulsar reformas neoliberales que ellos creen pueden producir disturbios, alto desempleo, fracasos bancarios y devastación de las clases obrera y media. No es esa una agenda con la cual alguien pudiera esperar ser elegido en una votación democrática..." En el párrafo anterior señala como una de las funciones del Estado "reducir las brechas sociales que existen entre ricos y pobres y que son las más amplias en el mundo" (ANEP, nov-dic., 1997; p. 19).

Este párafo viene a indicar, desde la posición liberal que mantiene la revista, la complejidad del papel del Estado en un entomo de globalización que, dejado al libre juego del mercado, tiende a profundizar la pobreza estruclural, la marginación social, incluso, el deterioro ecológico, además de la pérdida de múltiples valores tradicionales, tal como se ha descrito en otro documento: "El neoliberalismo en América Latina".

Al comentar los factores de la globalización, este documento afirma que "el neoliberalismo produce efectos estructurales que generan pobreza. El neoliberalismo, hoy día, al oponerse a la intervención redistributiva del Estado, perpetúa y acrecienta la desigualdad socioeconómica tradicional. El neoliberalismo introduce el criterio de que solamente el mercado posee la virtud de asignar eficientemente los recursos y fijar a los diversos factores sociales los niveles de ingreso. Se abandonan así los esfuerzos por alcanzar la justicia social mediante una estructura progresiva de impuestos y una asignación del gasto público que privilegie a los más desfavorecidos, dejando de lado los intentos por la democratización de la propiedad accionariada o la reforma agraria integral". (Realidad, No 54; p. 751...)

En forma tímida el plan de nación, al señalar las funciones del Estado, agrega este párralo: "También debe actuar de manera más directa y programálica para superar los desequilibrios históricos en el acceso de los diversos sectores a bienes y servicios básicos para una vida digna" (p. 24). Como el plan de nación se ha concentrado en los problemas internos a nuestras fronteras requiere, en su aplicación, enriquecerse y tomar en cuenta los efectos económicosociales del "huracán de la globalización". A los textos citados conviene agregar la denuncia que Juan Pablo II formuló contra el capitalismo en su reciente viaje a Cuba: "Resurge en varios lugares una forma de neoliberalismo capitalista que subordina la persona humana y condiciona el desarrollo de los pueblos a las fuerzas ciegas del mercado, gravando desde sus centros de poder a los países menos favorecidos con cargas insoportables... De esta manera se asiste al enriquecimiento exagerado 
de unos pocos a costa del empobrecimiento creciente de muchos, de forma que los ricos son cada vez más ricos y los pobres cada vez más pobres".

La lectura del plan de nación necesita complementarse con este horizonte del entomo mundial, sometido a determinado modelo político y a determinados valores cconómicosociales. Por ello son varios los puntos de posible divergencia en la lectura del plan de nación así como en las medidas por recomendar. El plan de nación habla de la "pobreza-estructural" como eje central del nudogordiano; pero no menciona su contraparte histórica Iradicional, cual es la "riqueza-estruclural". No existe la primera sin la segunda y en los documentos cilados vemos que las medidas neoliberales tienden a incrementar esta desigualdad. En otras palabras, y esto sí lo indica el plan de nación, no pueden identificarse los conceptos de crecimiento y desarrollo, como que el primero lleve espontáneamente al segundo, cuando la historia muestra que tienden a dislanciarse. "Bajo este criterio, queda claro que el crecimiento económico no es ni puede ser el fin del desarrollo económico, sino sólo uno de los componentes para lograrlo. Por consiguicnte, si el crecimiento no es parte de un proceso integral de desarrollo, puede llegar a favorecer el mantenimiento de las condiciones de pobreza, el deterioro del medio ambiente, los desequilibrios regionales y el debilitamiento de la capacidad productiva. No hay que olvidar, como lección histórica, que la conflictividad que vivimos en la década de los ochenta fue precedida, en términos generales, por casi treinta años de crecimiento económico" (p 10).

En la página siguiente, el plan de nación afirma que no ha jugado la "ilusión del rebalse". Estas líneas del presente documento vienen a cuestionar la postura no sólo oficial, sino de los organismos internacionales, que siguen repitiendo que nuestra economía es sana, fuerte y modelo a imitar por otros países, en razón del simple crecimiento económico. En reciente artículo se ha tratado de mostrar que el crecimiento no es ahora la locomotora de nuestra economía. (ECA, 1997; pp. 799-817). Este es tema de actual debate. Como en el Grupo Gestor, juramentado el 13 de febrero en casa presidencial, hay miembros adscritos a distanciadas ideologías, son de prever fuertes tensiones en la lectura del plan y las medidas por recomendar. Lo más importante es que la nación, en sus grupos representativos, está invitada a participar con sus opiniones y propuestas. Como en tiempos pasados, habrá grupos e instituciones que deberán ser "la voz de los que no tienen voz y la voz contra los que sí lienen voz".

Orientando un debate, que ojalá llevase a cierto nivel de consenso, en este mismo número de la revista se formula una sugerencia al neoliberalismo: "haga su autocrítica". Se trata de enfrentar a su ortodoxia con los efectos históricos de sus políticas, que incluso en el primer mundo están generando mayor desigualdad, bolsones de pobreza, insolidaridad social, y generan ya el rechazo y la protesta. Los testimonios autorizados muestran que ya comienza a declinar la euforia de los logros neoliberales. El mismo presidente del Fondo Monetario Internacional, 
Michel Camdessus, confiesa que "hemos pasado de un fundamentalismo del Estado a un fundamentalismo del mercado".

El plan de nación se presenta en un año preelectoral. Como esta propuesta ha recibido el parabien inicial, es normal que los partidos polílicos, asociaciones empresariales y laborales, otras agrupaciones sociales $y$, sin duda, institulos de investigación, traten de basarse en estos lineamientos generales. Pero también es normal esperar que a medida que se pase de los principios generales a las aplicaciones concretas aparezcan las divergencias, tanto en el interior del "grupo gestor" como en el diálogo más abierto nacional. Aparte de que el plan de nación integra cinco niveles, $y$ en el interior de cada uno puedan darse lecturas diferentes, persisten temas globales, como la naturaleza del "nudo-gordiano", el rol del Estado, su modernización, el modelo económico..., que se prestan a posturas entre diversas y antagónicas, en función del credo oficial. Estos son los claroscuros de la concertación nacional.

Una pregunta concreta es si el plan general de nación debe también integrar un plan (ministerio) de desarrollo económico y social. El gobierno actual dernuyó ese ministerio al inicio de su mandato; no deja de ser alģo irónico que la presentación del plan de nación se tuviera en el Ministerio de Asuntos Exteriores, cuando tanto su contenido como sus destinatarios eran temas más propios de un "ministerio de asuntos interiores". Pareciera que en los discursos del presidente, en 1997, había una reconciliación con la planeación económica y una difuminada autocrítica del error cometido.

Una palabra clave en este documento es el concepto de nación. Hablar de nación, de sus valores, tradiciones y sus personas tiene ahora una transcendencia especial, porque con la globalización neoliberal peligra la misma identidad nacional. El huracán de la globalización no sólo abate las fronteras geográficas con sus flujos de mercancías y capitales, sino que los monopolios de la informática y medios de comunicacion social imponen su visión de la realidad, imponen su verdad, inyectan nuevos principios hedonistas y mercantilistas (la moneda es el álgebra de toda la aclividad humana) y van deslavando las mejores tradiciones y valores ancestrales. Peligra la identidad política, económica y también la identidad ético-cultural, inmersas todas ellas en el anonimato del mercado mundial.

Debemos felicitamos de que este plan de nación haya recibido un parabien inicial porque, con otra traducción, la población siente que "hay que cambiar para mejorar". Debemos tomar en serio la tarea a la que se nos invita, porque -entre líneas- este plan de nación nos viene a decir que vuelven a estar presentes y a recrudecerse las causas internas que dieron origen a la guerra civil. Más vale un debate democrático que una contienda armada. 